\title{
IMPACT OF THE QUALITY OF SPACE OF LEARNING ENVIRONMENT ON THE QUALITY OF LIFE OF AUTISTIC CHILDREN :

\author{
Insights from three selected schools form Kandy, Sri Lanka
}

\author{
PREMATHILAKE. K.W..H.K. ${ }^{1}$ \& HETTIARACHCHI A.A. ${ }^{2}$ \\ 1, 2University of Moratuwa, Katubedda, Sri Lanka \\ 194himz@gmail.com, 2anishkah@uom.lk
}

\begin{abstract}
Children with Autism Spectrum disorder (ASD)are found to struggle with diverse challenges in achieving quality of life in their education environments. In view of this the current investigation looked in to the impact of the quality of space in their learning environments in enhancing the Quality of life of Autistic children. Two types of school environments that accommodate students with ASD were examined namely, a special education school (A) and two mainstream schools with special educational units (B \& C) in Kandy, considering 10 participants from each school $(\mathrm{n}=30)$. Inclusive design parameters were examined by a photographic survey and observations by the investigator and recorded via a 5-point Likert scale based on their level of presence. Pediatric Quality of Life Inventory (PedQL) was adopted to measure quality of life of participants. School A demonstrated the highest averages of for quality of space $(65 \%)$ as well as quality of life ( $61.7 \%)$ while C ( $34 \% / 48.3 \%)$ and B ( $30 \% / 44.7 \%)$ showed lower averages respectively. Accordingly, the study observed a clear relationship between the Quality of Space and the Quality of Life of children with ASD, highlighting the potential of enhancing the quality of life of the students with ASD by improving the quality of space of local schools.
\end{abstract}

Keywords: Autism Spectrum Disorder, Quality of Space, Quality of Life, Paediatric Quality of Life Inventory

\subsection{RESEARCH PREMISE}

Receiving proper education is a crucial aspect of a better quality of life for any child. Unfortunately, children with conditions like Autism Spectrum disorder who require special attention confront more obstacles compared to normal peers in receiving the basic needs for education. Fortunately, the modern world realizing this problem, has accepted these differences of children with special needs and taken a critical step towards a better quality of life (Abouelsaad, 2017). In view of this, the notion of inclusion is an excellent approach towards equal, balanced, non-discriminatory as well as healthy mode of education for children with such special needs. This research aims to investigate the current status of accommodating students with Autism Spectrum Disorder into the educational environment and to identify the way forward to support a sustainable as well as inclusive educational system UNESCO, 2003). The nature of buildings and their attributes of space with reference to the educational environments of Autistic Children can have a strong influence on their quality of life (Mostafa)2014.

\subsection{RESEARCH OBJECTIVES}

This study intends to research the interrelationship of the quality of architectural spaces and the quality of life of students with Autism spectrum disorder.

\section{Behavioral Characteristics of Students Towards Inclusive Design Approach}

\subsection{STUDENTS WITH SPECIAL EDUCATIONAL NEEDS}


The term special educational needs (SEN) is a legal definition that refers to students with learning difficulties that makes it harder for them to continue learning activities as same as a student in general. SEN includes a range of needs such as mental and physical disabilities as well as cognition or educational impairments (OECD, 2012). According to 'special education needs, code of practice' the special needs of students have been categorized, especially for the purpose of education.

\subsection{UNDERSTANDING THE USER}

"Autism is a severe disorder of communication, socialization and flexibility in thinking and behavior, which involves a different way of processing information and of seeing the world." (Jordan, R. 1999)

Autism Spectrum disorder can be defined as a serious neurodevelopment disorder that impair one's ability to interact and communicate with others. Moreover, this condition of children includes restricted repetitive behavioral patterns. This condition appears in the first three years of the life of a child, being the most severe developmental disorder. Autism Spectrum Disorder affects each child differently and to a varying degree (Issa, 2017). The latest identified types of Autism spectrum are as follows,

\subsubsection{Asperger's Syndrome}

Children with this condition mainly tends to face difficulties when understanding and interpreting social cues. Some children develop obsessive interests in certain specific objects or high level of intelligence in a certain field, while some children may experience sensory challenges. Often this disorder gets misdiagnosed with Attention Deficit Disorder and Obsessive Compulsory Disorder (OCD).

\subsubsection{Rett Syndrome}

This type of disorder only affects girls and is apparent when they reach 6 months of age. Similar characteristics as other forms of autism are observed and further symptoms like seizure, difficulty in breathing, mental retardation, growth delays and grinding teeth could be observed in severity.

\subsubsection{Childhood Disintegrative Disorder}

This is a rare form of autism and might be visible only after 2 years of age. This condition could be tough and confusing for parents. Sudden breakoff of speaking and interacting could be the initial symptoms of the disorder (Molecular Autism, n.d.).

\subsubsection{Kanner's Syndrome}

Also known as classic autistic disorder. Symptoms of standard autism behavior are shown in this condition such as communication difficulties, less or no eye contacts etc. (Pearce, 2007)

\subsubsection{Pervasive Developmental Disorder}

This syndrome is a mild form of autism and children with this condition easily cope with their challenges than one's with more severe types of autism (Cohen, 1997).

\subsection{ARCHITECTURAL CONSIDERATIONS}

School education is the second phase out of the four different stages of education currently practiced in Sri Lanka namely;

- Early childhood care and education.

- General education or school education.

- University education and,

- Technical or vocational education.

\subsubsection{Schools for differently abled students}

According to the Government of Sri Lanka, four educational options has been provided for differently abled children. 
- Special schools.

- Special units attached to mainstream schools.

- Inclusive mainstream schools.

- Special resource centers attached to mainstream schools (provides specially literacy related additional support).

The Ministry of Social Welfare, has specifically mentioned the necessity of the students with disabilities to be educated in special education units (SEU) or ordinary classrooms in mainstream schools. (National policy on Disability, 2003)

"Inclusion increases participation in learning and reduces exclusion within and from education" (UNESCO, 2003).

\subsection{INCLUSIVE SCHOOLS}

An inclusive school is an educational setting without any discrimination or exclusion towards a single student. Moreover, inclusive education is defined as a practice where students with complex identities are respected and valued (Hall et al, 2004). Consequently, it can be recognized as a place that the differences are respected and abilities are appreciated of every individual, supporting their needs and desires which helps to achieve a socially sustainable environment. Thus, in this process, schools with inclusive practices manifest a range of benefits for the whole school community. A shift in attitudes towards children with disabilities and special educational needs and positive changes in children's behavior due to improved educational settings are few of them as per described in the book, 'Inclusive School Design' (Hrekow., Clark \& Gathorne-Hardy, 2001)

\subsection{DESIGN REQUIREMENTS FOR AUTISM}

The idea of creating sustainable spaces for Autistic users progresses together with the universal concept of inclusion. Mostafa $(2008,2014)$ presented seven principles as a design development tool through the ASPECTSS Index. Furthermore, it is a set of criteria that can be followed in designing and assessing the built environment for individuals, especially students with the Autism Spectrum (Mostafa, 2008, 2014).

1. Acoustics - This is the most influential feature that impacts autistic behavior. The acoustical control needs to vary depending on the activity and the stimulation level of the space.

2. Spatial sequencing - The arrangement of spaces in a logical order depending on the usage of each space. Minimum distractions and one-way circulation strategies are looked at through this criterion.

3. Escape spaces - This is a sensory neutral space located in a quiet place, to be used by the autistic user for respite in over simulative circumstances.

4. Compartmentalization - Aims at defining and limiting the sensory environment. This could be achieved by including clearly defined functions with subsequent sensory quality. The separation could be as simple as through furniture arrangements, level differences, and material variations.

5. Transition zones - The main purpose of this criteria is to provide space and time for an autistic user to recalibrate his or her senses while moving from a certain level of stimulus to another.

6. Sensory zoning - The idea of designing spaces considering sensory qualities rather than the usual architectural approach. As an example, spaces could be grouped into high stimulus areas as physical therapy and low stimulus area as speech therapy and computer skills.

7. Safety - One of the most important concerns when designing spaces for children.

The research 'design across the spectrum: play spaces' done by Owen (2016) facilitates inspiring solutions that creates the relationship between students with Autism Spectrum Disorder and architecture namely; structuring the unstructured, crossing the threshold, spaces within spaces, active engagement, thinking in pictures, sensory diversity, stepping stone to social interaction and props to release the imagination. Beaver (2006) in his writing 'Breaking the Mould' presented a set of fundamental aspects that need extra attention when designing for autistic users. He stressed out the fact that building regulations or typical architectural approach is not the right solution for responsive designs. 


\subsection{QUALITY OF LIFE PREDICTORS FOR AUTISTIC CHILDREN}

The quality of life can be defined as the perception of an individual about the life position in respect to their goals, concerns, believes and standards in the context they live with a particular culture and values (WHO). Consequently, quality of life can be identified as a subjective assessment of the relationship of the context, an individual currently experiences. According to WHO, quality of life is measured under four main domains as, physical (seven items), psychological (six items), social (three items) and environment al (eight items).

\subsubsection{Paediatric quality of life inventory (PedQL)}

This is a model derived by Verni (1998) and used by researchers in measuring the life quality of Autistic children which can be both used as a self-report and parents proxy report. It consists of 4 main domains covering a list of aspects which might cause problems in functioning of Autistic children affecting their life quality, namely problems with physical functioning, emotional functionating, social functioning and school functioning which segregates into 23 sub items altogether as below.

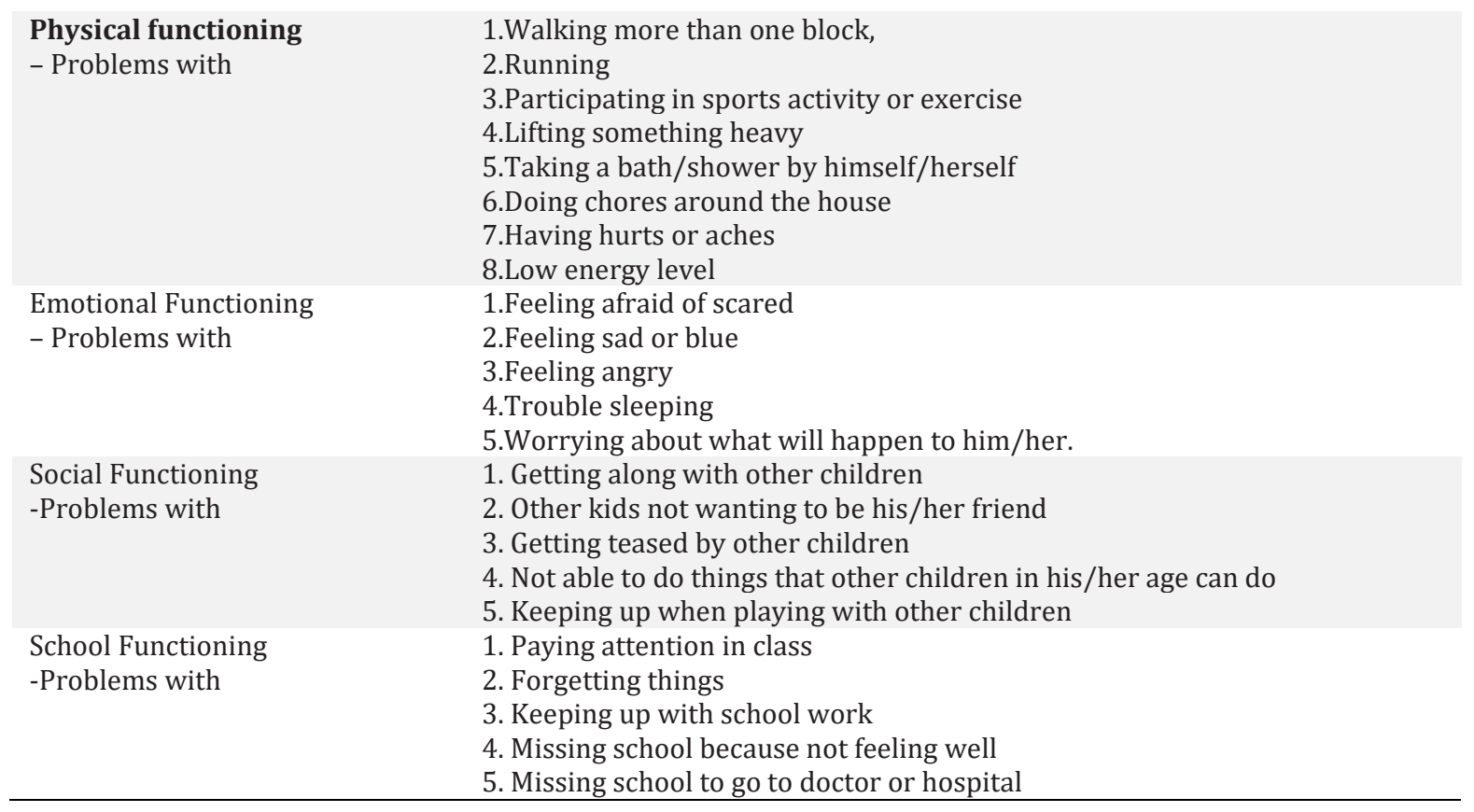

Table 1 - Parameters of Pediatric Quality of Life inventory - Version 4.0 (Verni, 1998)

These aspects are assessed through a scale from $0-4$ allowing the participants to rate the items stating as if the item was ; 0 - never a problem, 1 - almost never a problem, 2- sometimes a problem , 3 - often a problem, 4 - almost always a problem.

\subsection{RELATIONSHIP OF THE PHYSICAL ENVIRONMENT AND THE QUALITY OF LIFE OF AUTISTIC CHILDREN}

2.8 .

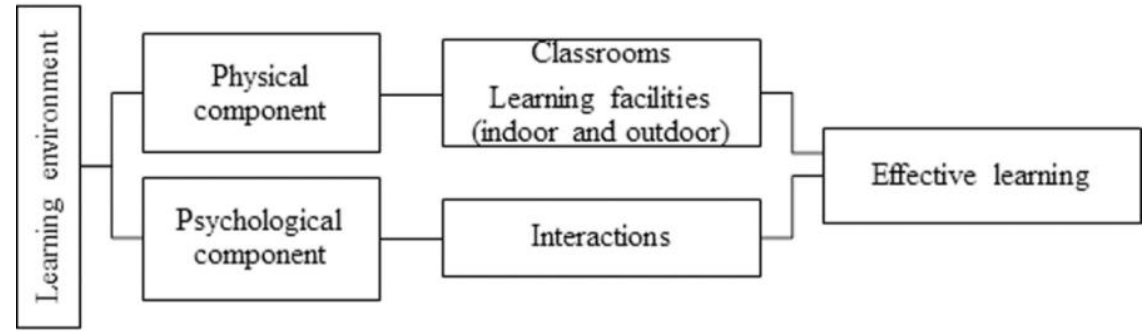

Figure 1, Elements of learning environment

(Source: Ghazali, R., et al, 2018) 
The importance and the effectiveness of the physical learning environment towards the behavioral improvements of children has been well established (Shaari \& Ahmad, 2016). Thus, the physical learning environment can no longer be disregarded. Moreover, built environment can be recognized as one of the major determinants of the learning process of students (Ghazali, R., et al, 2018). On the other hand, physical component' and 'psychological component' were identified as the two major elements of a learning environment by Kilgour (2006) and these two components help to improve the learning process of a child by complementing each other (Ghazali, R., et al, 2018) .

A set of inclusive Architectural design parameters were identified referring to previous literature, namely zoning, acoustics and lighting, escape spaces, transitional spaces and their associated 21 sub parameters as shown below.

\begin{tabular}{|c|c|c|}
\hline Source of reference & $\begin{array}{l}\text { Main } \\
\text { parameter }\end{array}$ & Sub parameters \\
\hline Mostafa (2014) & Zoning & 1.Availability of a simple layout which is not disorienting \\
\hline Issa (2017) & & $\begin{array}{l}\text { 2.Availability of spaces grouped as high stimulus and low } \\
\text { stimulus areas }\end{array}$ \\
\hline \multirow{4}{*}{$\begin{array}{l}\text { Shafik and Abouelsaad, } \\
\text { (2017) }\end{array}$} & Way finding & 3.0ne-way circulation system \\
\hline & & 4. Minimum changes in levels \\
\hline & & 5. Picture exchange communication \\
\hline & & 6. Unavailability of long corridors \\
\hline
\end{tabular}

\begin{tabular}{|c|c|c|}
\hline Beaver (2006) & Acoustics and & 7.External noise permeation level \\
\hline \multirow{2}{*}{$\begin{array}{l}\text { Shafik and Abouelsaad, } \\
\text { (2017) }\end{array}$} & \multirow[t]{6}{*}{ lighting } & 8. Availability of internal echoes \\
\hline & & 9. Availability of carpets \\
\hline \multirow{4}{*}{ Mostafa (2014) } & & 10. Availability of Acoustic ceilings \\
\hline & & 11. Avoiding flickering lights and proving soft lighting \\
\hline & & 12. Availability of shading devices or mechanisms to avoid glare \\
\hline & & from direct sunlight \\
\hline \multirow[t]{2}{*}{ Mostafa (2014) } & \multirow[t]{6}{*}{ Escape spaces } & 13. Availability of a space/room to escape to \\
\hline & & 14. Above room/space being used solely for this purpose \\
\hline \multirow[t]{4}{*}{ Issa (2017) } & & 15.Placemet of the escape space; whether it is situated in a safe \\
\hline & & $\begin{array}{l}\text { 16. Availability of an alternative to the escape room/ space; e.g - } \\
\text { the garden }\end{array}$ \\
\hline & & $\begin{array}{l}\text { 17. Availability of different items inside this space; blankets, } \\
\text { cushions, headphones to listen to music .etc. }\end{array}$ \\
\hline & & 18. Ability to customize the place \\
\hline \multirow[t]{4}{*}{ Mostafa (2014) } & \multirow[t]{4}{*}{$\begin{array}{l}\text { Transitional } \\
\text { spaces }\end{array}$} & $\begin{array}{l}\text { 19.Availabilty of transitional spaces in between high stimulus } \\
\text { and low stimulus areas }\end{array}$ \\
\hline & & 20.Transition zones (gardens or sensory curriculum rooms) \\
\hline & & $\begin{array}{l}\text { instead of one-way circulation, when one-way circulation is not } \\
\text { possible }\end{array}$ \\
\hline & & $\begin{array}{l}\text { 21. Availability of, textured pathways, water play, sand pits, } \\
\text { garden. (Schleien et al, 1991) }\end{array}$ \\
\hline
\end{tabular}

Table 2 - Parameters pertaining to quality of space/place predictors for Autistic children

Through the study, the main four parameters, Zoning, Acoustics and Lighting, Escape Space and Transitional Space formation were considered to determine the Quality of Space.

Considering the parameters of Quality of life and quality of space, below theoretical framework was derived ( figure 2). 


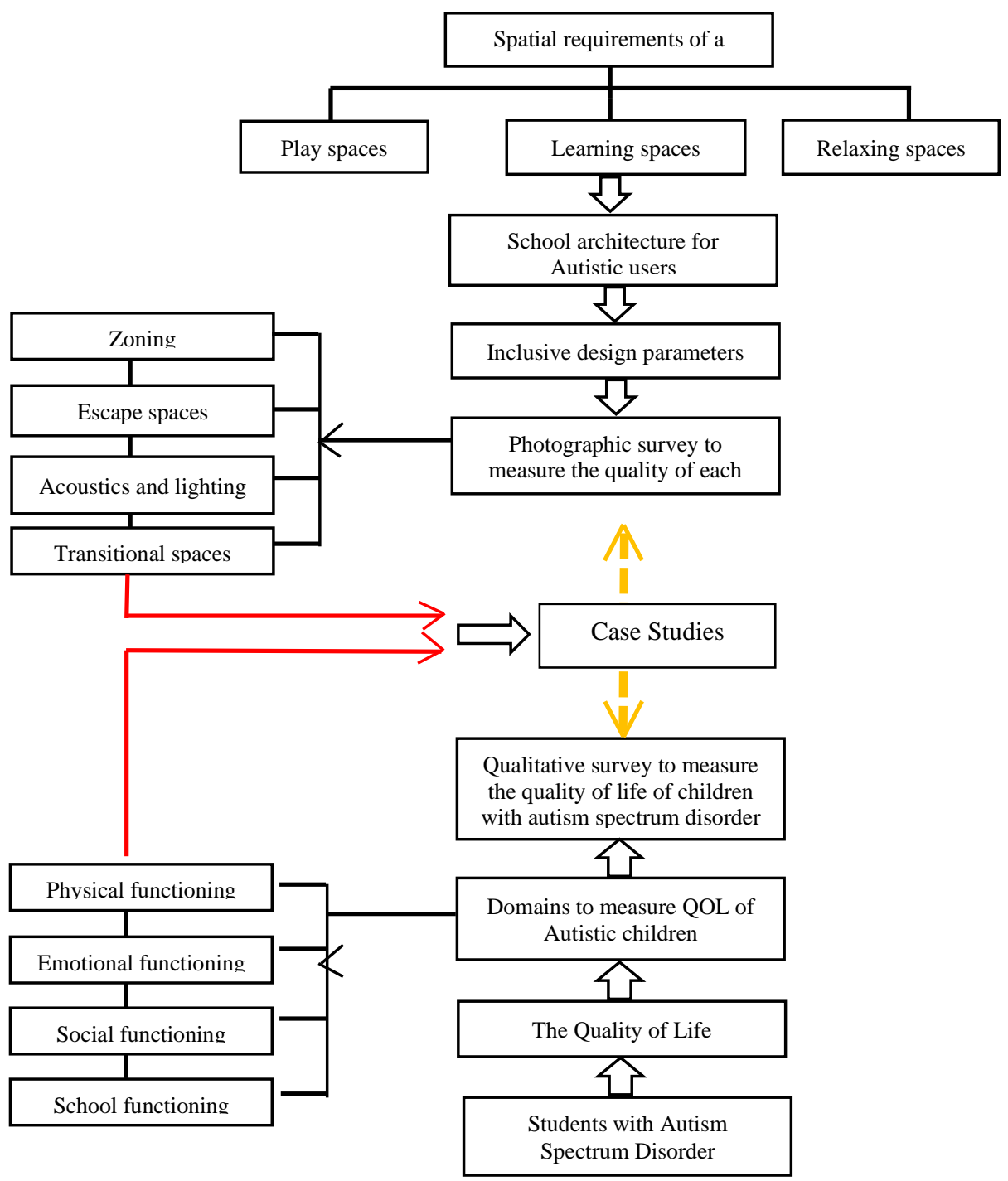

Figure 2, Theoretical Framework

\section{Research Design and methodology}

\subsection{CRITERIA FOR CASE STUDY SELECTION}

In order to make a comparison of the level of inclusiveness and of the quality of life of students, two types of schools were selected. The main consideration in selecting the research sample was the diagnosis of every research subject from autism spectrum disorder. Therefore, schools with a higher number of sample population from each of above typologies was selected from the Kandy district.

\subsection{METHODOLOGY}

The research was executed based on a qualitative case study approach. The study mainly investigated the manner as to how the built environment and its spatial quality affects the life quality of children with Autism Spectrum disorder in selected schools that accommodates students with ASD from Kandy district. Two types of school environments that accommodate students with ASD were examined namely, special education schools and special educational units in mainstream schools. One school was selected under the special school category ( School A) while two schools were selected as mainstream schools with a special unit ( School B and School C). 10 participants per case study were selected $(n=30)$ in order to investigate the interrelationship of the Quality of Life with the spatial quality of each case study. All the schools for the research were from suburban context. Participant's parent's/guardian's personal consent and willingness to provide the necessary personal data regarding their quality of life was obtained. 
To collect data related to the Quality of Life of participants Pediatric quality of life standard inventory ( PedsQL) was adopted . The parents proxy report of the standard questionnaire of pediatric quality of life inventory was used to collect data under three areas;

Section A- Demographic data

Section B- Physical functioning

Section C- Social functioning, Emotional functioning and School functioning

Parameters pertaining to quality of space/place predictors for Autistic children were recorded through observations, interviews and a photographic survey to investigate the existing condition of the built environment in three selected schools. The 21 parameters identified through literature (table 2) were observed and rated by the investigator based on the level of availability on a 5 point Likert scale of which 1 stands for the least and 5 for the highest level.

\subsection{METHOD OF DATA ANALYSIS}

The qualitative variables gathered through data collection were transferred into quantifiable indicators. The quality of each spatial requirement was represented with a percentage value ranging from $0 \%$ to $100 \%$. The scoring algorithm in the pediatric quality of life inventory itself was used to analyze the data collected from the questionnaire. Scale scores for each domain were obtained and initially for ease of compatibility, items were reversed scored and linearly transformed to a 0-100 scale in such a way that the higher scores indicate better quality of life. Consequently, 0 was converted as $100,1=75,2=50,3=25$ and $4=0$. The mean values were obtained from sum of the items / the number of items.

\section{Findings, analysis and discussion}

\subsection{ANALYSIS AND THE COMPARISON OF QUALITY OF LIFE OF STUDENTS OF THE SCHOOLS}

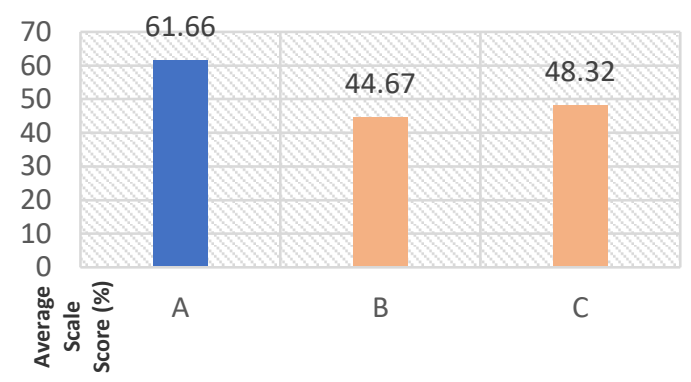

Figure 3, Summarized average scale scores of each school - Quality of LIFE

The average quality of life obtained from the total scale scores of the participants from the selected case under special school typology (A) is $61.66 \%$ and the same average for case study ' $\mathrm{B}$ ' is $44.67 \%$. The average value obtained from the total scale score of the sample group of the case study ' $\mathrm{C}$ ' is $48.32 \%$. Therefore, a higher quality of life was observed in students of the case study ' $\mathrm{A}$ ' than the sample groups from the special units of the case studies ' $\mathrm{B}$ ' and ' $\mathrm{C}$ '. (Figure 3)

\subsection{ANALYSIS AND THE COMPARISON OF THE QUALITY OF SPACES IN THE SELECTED SCHOOLS}

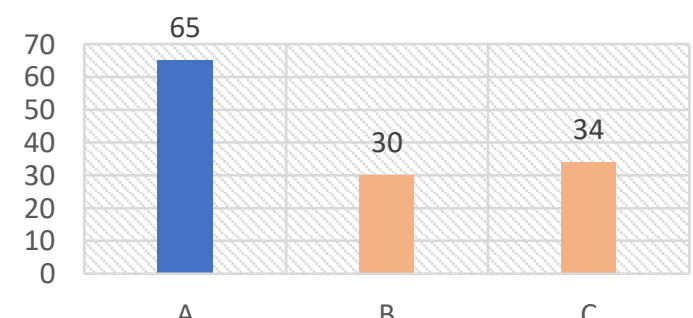

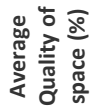

Figure 4, Comparison of the average - Quality of space in each school 
As evident by the percentage values gained by each school for the quality of space in order to accommodate students with Autism spectrum disorder tested, case study 'A' shows the highest average of 65\%, while the lowest average of $30 \%$ was obtained by case study 'B'. The comparison of the quality of space of all the schools is graphically presented below (Figure 4).

\subsection{THE RELATIONSHIP OF THE QUALITY OF SPACE TOWARDS IMPROVING QUALITY OF LIFE OF THE SUBJECT STUDENT POPULATION}

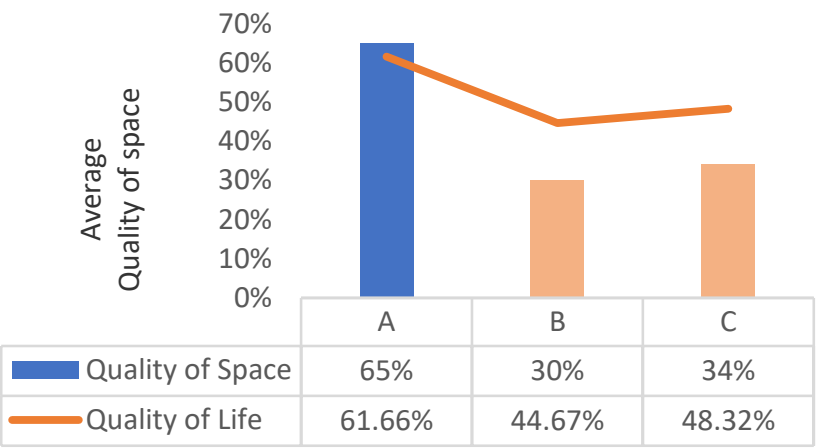

$70.00 \%$

$60.00 \%$

$50.00 \%$

$40.00 \%$

$30.00 \%$

$20.00 \%$

$10.00 \%$

$0.00 \%$

Figure 5, Relationship of quality of space and quality of life of each case study

The comparison between the Quality of Life and Quality of space percentages in the three schools tested an equally proportionate relationship. School A showed the highest average of $65 \%$ for the quality of space as well as an average of $61.66 \%$ for the quality of life. While the two mainstream schools with a special unit show lower averages respectively. Through literature, it has been identified that a sensory design results in creating positive impacts on the quality of life of Autistic children (Ghazali, R., et al, 2018) and how a learning environment with the required quality acts as a major determinant of the development of the learning abilities (Ghazali, R., et al, 2018), visible and proved through the findings of the current study as well. Therefore, it is evident that even in the local context, under the existing conditions, the quality of life of the students with Autism Spectrum Disorder has a direct impact from the built environment, especially from their learning environment.

The observations made by the investigator revealed that unavailability of any treatment facility attached to the learning environment was one of the most significant reasons that resulted in a spatial quality of less than $40 \%$ and a Quality of Life of less than $50 \%$, for the students, especially of the mainstream schools.

In the special units of the mainstream schools, the built environment needs to address more on installation of individual and escape spaces while improving on spaces to gradually transit from one to another.

In the current situation students in the special units were observed to be easily getting overwhelmed due to the congested atmosphere in the classroom resulting in a significant decrement in the quality of life.

Accordingly, it is understood through the study that rather than producing learning environments repeatedly, it is crucial to upgrade the existing school environment to reach the required level with recommended facilities as an initial step.

\section{Conclusion}

Through the findings from three cases tested, a clear relationship between the Quality of Space and the Quality of Life was observed. An increment in the Quality of Life of the students with ASD was observed along with an increment in the spatial quality of their learning environments.

Thus, the study encourages and recommends the involvement of architects and professionals of the field, in the process of developing inclusive built environments. This approach can provide the students with ASD, the opportunity to use the built environment without any barriers, resulting in a better Quality of Life. 
Moreover, the study can be further expanded beyond the limitations of the current research with much larger sample groups and cases selected from different regions of the country so that the findings can be generalized to the local context as a whole.

It can be concluded that the existing conditions of the educational settings to accommodate students with Autism Spectrum Disorder are at a non-favorable condition in general. Therefore, same as the approaches towards inclusion through the curriculum, attention should be provided to improve physical facilities for the students by incorporating the recommended 21 spatial requirements established via research. Through the findings and the observations made it is evident that with necessary improvements added to the local schools, it is possible to reach the level of inclusiveness that is globally recommended, and improve the quality of life of the students with Autism Spectrum Disorder while serving social sustainability.

\section{References}

Abeywickrama, S. P., Jayasinghe, I. K., Sumanasena, S. P. (2013). Excluded in Inclusive Schools. Experiences of Children with Disabilities, their Families and Teachers in Sri Lanka, 24(1), 115-129. doi:10.5463/DCID.v24i1.172

Beaver, C. (2006). Designing environments for children and adults with ASD. Autism Safari, 2nd World Autism Congress and Exhibition.

Fletcher, H. (2006). The principles of inclusive design. London: Lithoshere in Starfine.

Hrekow, M., Clark, H., \& Gathorne-Hardy, F. (2001). Inclusive School Design. Accommodating Pupils with Special Educational Needs and Disabilities in Mainstream Schools, Department for Education and Employment, UK.

Issa, S. M. (2017). Architecture and Students with Autism. Exploring Strategies for Their Inclusion in Society Mainstream, 11(8), 2141-2146. doi: 10.5281/zenodo.1131876

Joshua K. Harrower \& Glen Dunlap. (2001). Including Children with Autism in General Education classrooms: A review of effective Strategies. Behaiour modification, 765-767.

Mayo Clinic, (n.d.). Autism Spectrum Disorder. Retrieved from https://www.mayoclinic.org/diseasesconditions/autism-spectrum-disorder/symptoms-causes/syc-20352928

Mcguire, J. M., Scott, S. S., Shaw, S. F. (2006). Universal design and its applications in educational environments, 27(3), 166-175. doi: 10.1177/07419325060270030501

Ministry of Education. (2013). Education First Sri Lanka. Battaramulla: Sisira Printway Private Limited.

Mostafa, M. (2014). Architecture for Autism: Autism aspectss ${ }^{\mathrm{TM}}$ in school design, Archnet-IJAR: International Journal of Architectural Research, 8(1), 143-158

National Association of Special Education Teachers. (n.d.). Types of Autism Spectrum Disorders. Retrieved from http://www.naset.org/fileadmin/user_upload/Autism_Series/Types_of_Autism_Spectrum_Disorders.pdf

Owen, C. (2016). Design across the Spectrum: Play spaces, Tasmania

Riser, R. (2012). Implementing Inclusive Education: A Commonwealth Guide to Implementing Article 24 of the UN Convention on the Rights of Persons with Disabilities (Second Edition). London: Charlesworth Press.

Shafik, Z. Y., Abouelsaad, A. S. (2017). Architectural design criteria for inclusive education schools. A toolkit to include the largest number of pupils with "different/special" needs

Stubbs, S. (2008). Inclusive Education; Where there are few resources. Oslo: The Atlas Alliance.

Thomas, G., Walker, D., \& Webb, J. (2001). The Making of the Inclusive School, Taylor \& Francis e-Library

UYAROĞLU, Đ. D. (2008). Architectural implications of community based/inclusive rehabilitation centers in the light of universal design (Master's thesis, Middle East technical university). Retrieved from https://www.researchgate.net/publication/338774288_Architectural_Implications_of_Communitybased_Inclusive_Rehabilitation_Centers_in_the_Light_of_Universal_Design

Varni,W.(1998). Pediatric Quality of Life Inventory, Version 4.0. Retrieved from https://www.pedsql.org/about_pedsql.html.

Whitehurst, T. (2006). The impact of building design on children with autistic spectrum disorders. Good Autism Practice, 7(1), 31-38.

Zhen-Huan, L., Qiao-Ling, X., Yong, Z., Xiao-Zhen, W. (2016). Quality of Life of Children with ASD, doi: 10.4172/21657890.1000183 